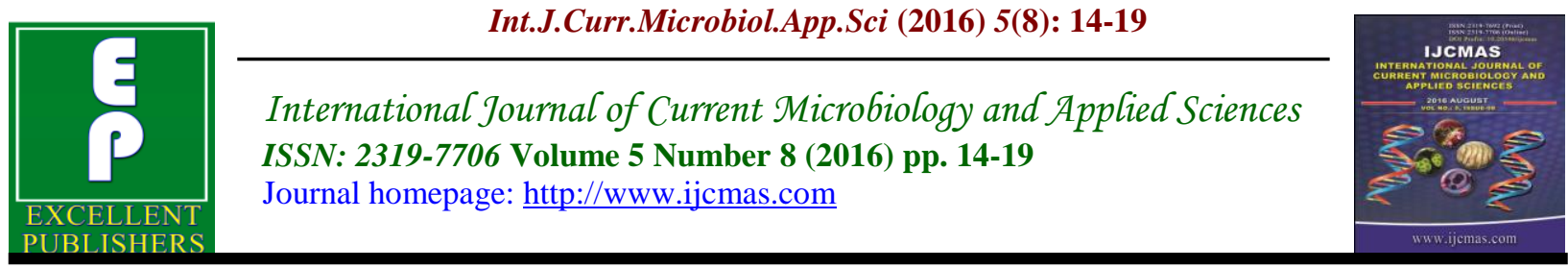

Original Research Article

http://dx.doi.org/10.20546/ijcmas.2016.508.002

\title{
Organism causing Urinary Tract Infection with Special Reference to Staphylococcus saprophyticus
}

\author{
Amar C. Sajjan*, Krishnamurthy Sirigadha and G. Swetha \\ Department of Microbiology, Chalmeda Anand Rao Institute of Medical Sciences, \\ Karimnagar, Telangana, India
}

*Corresponding author

\begin{abstract}
A B S T R A C T
Keywords

UTI,

Staphylococcus saprophyticus, Antibiotic sensitivity testing.

\section{Article Info}

Accepted:

06 July 2016

Available Online:

10 August 2016

Staphylococcus saprophyticus once thought to have little or no importance in causing UTI (Urinary Tract Infection). It is the second most common pathogen after Escherichia coli causing 10-20 \% of all UTI especially in sexually active young woman. To know the prevalence of Staphylococcus saprophyticus and its antibiotic sensitivity testing. Mid stream urine sample collected and inoculated on MacConkey agar, blood agar and CLED agar. The organism identified by biochemical test and Novobiocin sensitivity test. Total 177 isolated from patients with symptomatic UTI, among them 26(13.13\%) isolates were Staphylococcus saprophyticus. Antibiotics like Vancomycin, Linezolid and Imipenem showed $100 \%$ sensitivity followed by Nitrofurantoin which is $84.61 \%$ and least being Ampicillin (26.92\%). The study showed predominance of Staphylococcus saprophyticus in sexually active young woman.
\end{abstract}

\section{Introduction}

Staphylococcus saprophyticus is recognized as one of the important causative organism of uncomplicated UTI among young and middle aged women especially who are sexually active. It is a Coagulase Negative Staphylococcus (CONS) that can adhere to uroepthilial cells causing local inflammatory process (Guidone et al., 2001). Previously it was thought CONS have little or no significance in causing UTI. Only in 1970s these species recognized as causing agent of UTI (Jhora et al., 2011). The complications following infections by this organism include acute pyelonephritis, septicemia, nephrolithiasis and endocardits (Hedman et al., 1991; Glimaker et al., 1988; Singh et al., 1990; Garduno et al., 2005). Staphylococcus saprophyticus is the second most frequent agent of UTI after Escherichia coli (Ferreira et al., 2012).

Current study is undertaken to know the prevalance of organism causing UTI and anti microbial susceptibility of Staphylococcus saprophyticus. 


\section{Materials and Methods}

This study was carried out in a tertiary care hospital in Karimnagar from March 2015 to February 2016. Midstream clean catch urine was collected from all age group and both sexes came with symptomatic UTI. Sample inoculated on to blood agar, Mac Conkey agar and CLED agar (Cystine Lactose Electrolyte Deficient medium) by Semi quantitative method using $2 \mathrm{~mm}$ bacterial inoculating loop. Organism isolated identified by colony morphology, Gram stain, catalase test, coagulase test and other biochemical tests and Novobiocin $(5 \mathrm{mcg})$ sensitivity testing. Antibiotic sensitivity test for all Staphylococcus saprophyticus isolates done by Kirby-bauer method using Mueller Hinton agar (Forbes et al., 2007; CLSI,
2015). Antibiotics used are Ampicillin (25 $\mathrm{mcg}$ ), Amikacin (10 mcg), Cefotaxime (30 $\mathrm{mcg}$ ), Imipenem (10 mcg), Linezolid (30 $\mathrm{mcg})$ Nitrofurantoin (100 $\mathrm{mcg})$, Norfloxacin $(100 \quad \mathrm{mcg}), \quad$ Pipercillin /Tazobactam(100/10 mcg), Vancomycin(10 mcg).

\section{Results and Discussion}

The prevalence of UTI was found to be $10.87 \%$ in this study and this rate of prevalence is similar to Akram et al., (2007) $(10.86 \%)$ but little lower compared to Ahmed et al., (2012) (20.12\%). From above results it is observed that Staphylococcus saprophyticus is an important pathogen in sexually active young women.

Table.1 Frequency of isolated pathogens from urine $(\mathrm{n}=177)$

\begin{tabular}{|l|l|l|}
\hline Isolate & Number & $\begin{array}{l}\text { Percentage } \\
\mathbf{\%}\end{array}$ \\
\hline Escherichia coli & 117 & 59.09 \\
\hline Klebsiella pneumoniae & 35 & 17.67 \\
\hline Staphylococcus saprophyticus & 26 & 13.13 \\
\hline Staphylococcus aureus & 7 & 3.63 \\
\hline Pseudomonas & 6 & 3.03 \\
\hline Proteus & 5 & 2.52 \\
\hline Enterococci & 2 & 1.01 \\
\hline Total & $\mathbf{1 7 7}$ & $\mathbf{1 0 0}$ \\
\hline
\end{tabular}

Table I showed the frequency of isolated bacteria from urine sample. A total of 177(10.86\%) organism were isolated among 1627 urine sample screened. Majority of the isolates were Escherichia coli $(59.09 \%)$ followed by Klebsiella pneumoniae which accounts for $17.67 \%$ and Staphylococcus saprophyticus (13.13\%). 
Table.2 Age and Sex distribution of S. saprophyticus

\begin{tabular}{|l|l|l|l|}
\hline Age (in years) & Female & Male & Total \\
\hline$<18$ & $1(3.84 \%)$ & 0 & $1(3.84 \%)$ \\
\hline $18-45$ & $23(88.46 \%)$ & 0 & $23(88.46 \%)$ \\
\hline$>45$ & $1(3.84 \%)$ & $1(3.84 \%)$ & $2(7.69 \%)$ \\
\hline Total & $\mathbf{2 5 ( 9 6 . 1 5 \% )}$ & $\mathbf{1 ( 3 . 8 4 \% )}$ & $\mathbf{2 6 ( 1 0 0 \% )}$ \\
\hline
\end{tabular}

Table II shows the age \& sex distribution of the isolate $S$. saprophyticus. Maximum organisms were isolated from females which was $25(96.15 \%)$ and 23(88.46) isolates were predominant in age group between 18 and 45 years.

Table.3 Anti-microbial sensitivity pattern of S. saprophyticus ( $n=26)$

\begin{tabular}{|l|l|l|}
\hline Antibiotic & Sensitivity & Resistance \\
\hline Imipenem & $26(100.00 \%)$ & 0 \\
\hline Vancomycin & $26(100.00 \%)$ & 0 \\
\hline Linezolid & $26(100.00 \%)$ & 0 \\
\hline Nitrofurantoin & $22(84.61 \%)$ & $4(15.38)$ \\
\hline Amikacin & $19(73.07)$ & $7(26.92)$ \\
\hline $\begin{array}{l}\text { Pipercillin/ } \\
\text { Tazobactam }\end{array}$ & $18(69.23 \%)$ & $8(30.77)$ \\
\hline Cefotaxime & $14(53.84 \%)$ & $12(46.15)$ \\
\hline Norfloxacin & $11(42.30 \%)$ & $14(53.84)$ \\
\hline Ampicillin & $7(26.92 \%)$ & $19(73.07)$ \\
\hline
\end{tabular}

Above table shows that all isolates were sensitive to Imipenem, Vancomycin and Linezolid followed by Nitrofurantoin (84.61), Amikacin 19(73.07) and maximum resistance encountered Ampicillin (73.07\%)

Fig.1 Frequency of isolated pathogens from urine $(n=177)$

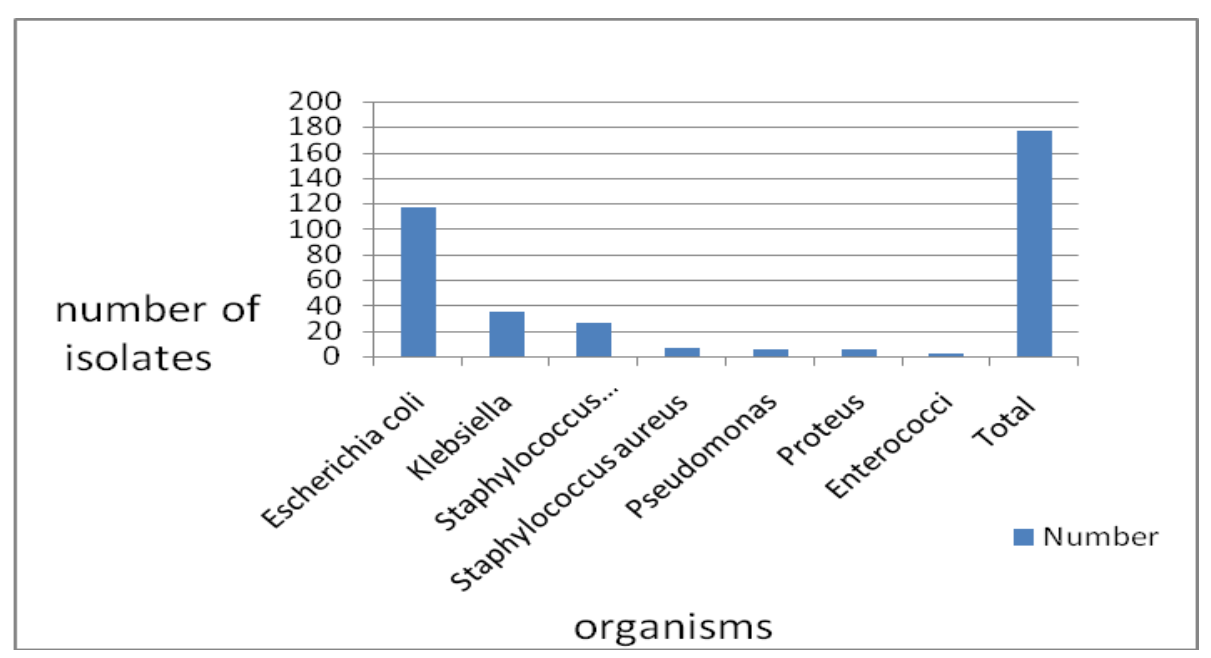


Fig.2 Age and Sex distribution

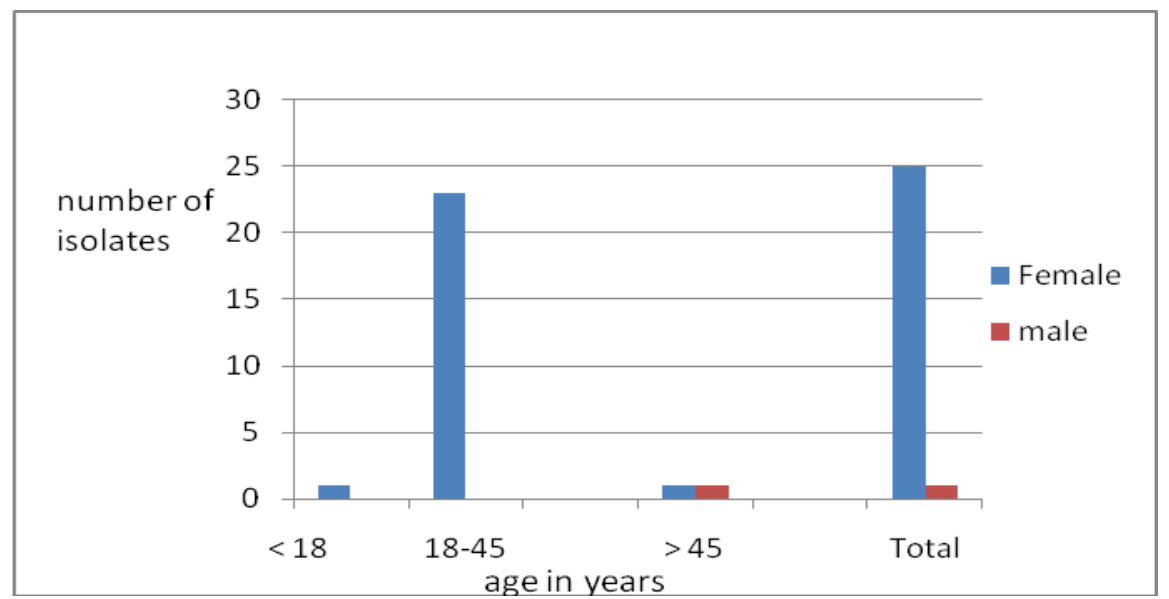

Fig.3 Antibiotic sensitivity testing by Kirby Bauer method

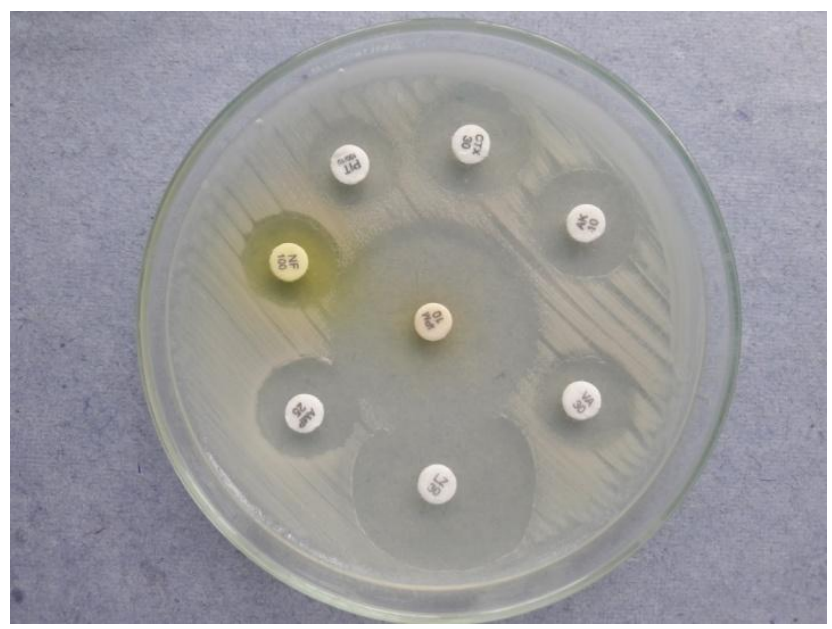

The present study findings in this study support previous studies. Prevalence of $S$. saprophyticus was $8 \%$ and $15.2 \%$ in a study done by Gupta et al., (1999) and Schneider PF et al., (1996) respectively while in our study it is $13.13 \%$. A study done by Onyemelukwe (2013) et al., in Nigeria showed that $93.8 \%$ of total $S$. saprophyticus were from young women aged between 15 and 45 years which is in accordance with our present study where as Rehman (2014) showed only one percent isolation but second most common isolate was Klebsiella pneumoniae which is similar to our study.
We have used Novobiocin disc to differentiate $S$. saprophyticus from other CONS as it is reported to be $100 \%$ sensitive and $96 \%$ specific and also simple and reliable (McTaggart et al., 1989). All 26 isolates were sensitive to Imipenem, Linezolid and, Vancomycin and least sensitive was Ampicillin which is similar to studies conducted by Akter (2013), Gupta (2013).

In conclusion, staphylococcus saprophyticus predominates in sexually active young women and it should be treated promptly to avoid complications. 


\section{References}

Ahmed, S.M., Jakribettu, R.P., Koyakutty, S. 2012. Urinary Tract Infections An overview on the Prevalence and the Anti-biogram of Gram Negative Uropathogens in A Tertiary Care Centre in North Kerala, India. $J$. Clin. Diag. Res., (Suppl); Vol-6(7): 1192-1195.

Akram, M., Shahid, M., Khan, U.A. 2007. Etiology and antibiotic resistance patterns of community-acquired urinary tract infections in $\mathrm{J} \mathrm{N} \mathrm{M} \mathrm{C}$ Hospital Aligarh, India. Annals of Clin. Microbiol. Antimicrobials, 6(4).

Akter, T., Mia, Z., Shahriar, M. 2013. Antibiotic sensitivity of pathogens causing urinary tract infection. Bangladesh Pharmaceutical J., 16(1): 53-58.

CLSI. 2015. Performance Standards for Antimicrobial Susceptibility Testing; Twenty-Fifth Informational Supplement. CLSI document M100S25. Wayne, PA: Clinical and Laboratory Standards Institute

Ferreira, A.M., Bonesso, M.F., Moddelli, A.L. et al. 2012. Identification of Staphylococcus saprophyticus isolated from patients with urinary tract infection using a simple set of biochemical tests correlating with $16 \mathrm{~S}-23 \mathrm{~S}$ interspace region molecular weight patterns. J. Microbiol. Methods, 91: 406-411.

Forbes, B.A., Daniel, Sahm, D.F. et al. 2007. Staphylococcus, Micrococcus and similar organisms. In:Bailey and scott's diagnostic Microbiology, 12 ed. St. louis: Mosby Elsevier; 254 264.

Garduno, E., Marquez, I., Beteta, A., et al. 2005. Staphylococcus saprophyticus causing native - value endocarditis. Scand J. infect. Dis., 37(9): 690-1.

Glimaker, M., Granert, C., krook, A. 1988. Septicemia caused by Staphycocus saprophytes. Scand J. Infect. Dis., 20: 347-845-53.

Guidone, E.B., toporovsk, J. 2001. Urine infection in adolescent. J. Pediatr., 77(supl.2): 165-169.

Gupta, K., Hooton, T.M., Wobbe, C.L., Stamm, W.E. 1999. The prevalence of antimicrobial resistance among uropathogens causing acute uncomplicated cystitis in young women. Int. J. Antimicrob. Agents, 11(3-4): 305-8.

Gupta, S., Agarwal, R., Bhooshan, S. 2013. Changing trends in resistance pattern as an alaram by bacteria before it's too late to treat. J. Dental and Med. Sci., 12(6): 55-60.

Hedman, P., Rigertz, O. 1991. Urinary tract infection caused by Staphylococcus saprophyticus. A matched case control study. J. Infect. Dis., 23: 1 .

Jhora, T.S., Paul, S. 2011. Urinary tract infection caused by Staphylococcus saprophyticus and their anti microbial sensitivity patter in young adult woman. Bangladesh J. Med. microbial., 5(01): 21-25.

McTaggart, L.A., Elliott, T.S. 1989. Is resistance to novobiocin a reliable test for confirmation of the identification of Staphylococcus saprophyticus? J. Med. Microbiol., 30: 253-66.

Onyemelukwe, N.F., Nwokocha, A.R.C. 2013. Staphylococcus saprophyticus infection as a cause of UTI in female adolescents in Enugu area, Nigeria. ISOR J. Dental and Med. Sci., 11(5): 37-40.

Rehman, S.S., Kanta, R.C., Kapur, I. 2014. Urinary tract infection due to Staphylococcus saprophyticus in 
young women. MRIMS J. Health Sci., 2(1): 5-7.

Schneider, P.F., Riley, T.V. 1996. Staphylococcus saprophyticus urinary tract infections: epidemiological data from western Australia. Eur. J. Epidemiol., 12(1): $51-4$.
Singh, V.R., Raad, I. 1990. Fatal Staphylococcus saprophyticus native- value endoccrdits in an intravenous drug addict. J. Infect. Dis., 162: 783-4.

\section{How to cite this article:}

Amar C. Sajjan, Krishnamurthy Sirigadha and Swetha, G. 2016. Organism causing Urinary Tract Infection with Special Reference to Staphylococcus saprophyticus. Int.J.Curr.Microbiol.App.Sci. 5(8): 14-19. doi: http://dx.doi.org/10.20546/ijcmas.2016.508.002 